\title{
Chemical compatibility testing of the entomopathogenic fungus Lecanicillium muscarium to control Bemisia tabaci in glasshouse environment
}

\author{
*A. G. S. Cuthbertson; L. F. Blackburn; P. Northing; W. Luo; R. J. C. Cannon; K. F. A. Walters
}

The Food and Environment Research Agency, York, England, UK

Received 27 Octobert 2009; $\quad$ revised 1 February 2010; accepted 20 February 2010; avaiable online 1 March 2010

\begin{abstract}
The potential for using the entomopathogenic fungus Lecanicillium muscarium to control the sweetpotato whitefly, Bemisia tabaci has been well established in previous studies under both laboratory and glasshouse conditions. In the current study, five chemicals were assessed for their compatibility with L. muscarium for control of $B$. tabaci under glasshouse conditions. On treatments following the sequential application of chemical product and fungus high mortality of second instar larvae was obtained (the known most susceptible B. tabaci life-stage to fungal infection). Sequential treatment of Savona and Certis spraying oil with L. muscarium produced $95 \%$ and $96 \%$ larval mortality, respectively. Commercially, unacceptable poinsettia foliage damage was recorded seven days post application of Agri-50E. Other plant foliage may prove more tolerant to this product. Incorporation of these chemicals with $L$. muscarium into integrated control programmes for B. tabaci control in glasshouses is discussed. Further information has been added to the knowledge base for the combined use of chemicals and fungi for the control of $B$. tabaci.
\end{abstract}

Keywords: Insecticides; Integrated pest management; Plant; Quarantine; Whitefly

\section{INTRODUCTION}

The sweetpotato whitefly, Bemisa tabaci Gennadius (Hemiptera: Aleyrodidae), is a major pest of economically important crops worldwide (Gerling et al., 1980; Nomikou et al., 2000). Damage can be caused directly by feeding on phloem sap or indirectly by the large amounts of honeydew produced lowering photosynthesis. Bemisia tabaci is also a vector of many plant viruses (Alegbejo, 2000: Simón et al., 2003). Within the United Kingdom (UK), B. tabaci continues to remain a notifiable pest subject to a policy of eradication if found on propagators' premises or on plants moving in trade, and of containment/eradication if outbreaks occur at nurseries (Cuthbertson, 2005). The UK has Protected Zone status against B. tabaci and eradication generally involves use of chemical insecticides. There are several active ingredients currently used in the UK for treating B. tabaci outbreaks (Sharaf, 1986; Buxton and Clarke, 1994; Cheek and Macdonald, 1994; Cannon et al., 2005), but with

凶*Corresponding Author Email: andrew.cuthbertson@fera.gsi.gov.uk Tel.: +44 (0) 1904 462201; Fax: +44 (0) 1904462111 chemical resistance being shown by $B$. tabaci populations (Prabhaker et al., 1985; Osborne and Landa, 1992; Cahill et al., 1994, 1996; Ahmad et al., 2002) an integrated strategy using both biological and chemical agents is required. The entomopathogenic fungus Lecanicillium muscarium has shown significant potential for incorporation into integrated pest management (IPM) programmes for the control of $B$. tabaci, where, second instar larvae have proven most susceptible to fungal infection (Cuthbertson et al., 2005a). Lecanicillum muscarium has also shown potential for control of $B$. tabaci larvae in glasshouses on a range of plant hosts, including poinsettia (Cuthbertson and Walters, 2005a; Cuthbertson et al., 2008a; Down et al., 2009). Previous investigations into chemical insecticide compatibility with $L$. muscarium have found varying results. Hall (1981) showed that chemicals such as pirimicarb and white oil could be 'tank mixed' with the fungus for the control of aphids, and similarly Cuthbertson et al. (2005b) proved that the fungus could be applied simultaneously with 
buprofezin, and also, when used sequentially with imidacloprid gave a high percentage mortality of $B$. tabaci second instar larvae.

The development of control strategies for nonindigenous insects within the UK is limited by legislation which precludes the intentional release of quarantine pests into ordinary experimental glasshouses (Williams and Walters, 2000; Cuthbertson et al., 2009a). As no outbreak site was identified for testing the efficacy of $L$. muscarium against B. tabaci, a designated quarantine glasshouse at The Food and Environment Research Agency, York, was used for experimental purposes. This study therefore, further investigates the compatibility of $L$. muscarium with a range of insecticidal products for control of second instar B. tabaci on poinsettia plants in UK glasshouses.

\section{MATERIALS AND METHODS}

Bemisia tabaci were cultured under quarantine conditions in perspex cages $(60 \times 60 \times 80 \mathrm{~cm})$ on poinsettia (Euphorbia pulcherrima c.v. Lilo Pink) plants at $23 \pm 1{ }^{\circ} \mathrm{C}$ following the method of Cuthbertson et al. (2005a,b, 2008a,b). The entomopathogenic fungus Lecanicillium muscarium was supplied as Mycotal from Koppert Biological Systems Ltd., UK. The selected insecticidal products to test were as follows: Majestik (natural plant extract, $2.5 \mathrm{~mL} / 100 \mathrm{~mL}$ water, Certis UK); Agri-50E (alginate/polysaccharide, $300 \mu \mathrm{L} / 100 \mathrm{~mL}$, Fargo Ltd, UK); Certis Spraying Oil (petroleum oil, 1 mL/100 mL water, Certis UK); Savona (fatty acids, 2 mL/100 mL water, Koppert Biological Systems Ltd, UK); Oberon (spiromesifen, 0.05 g/100 mL water, Bayer CropScience). Following the method of Cuthbertson and Walters (2005a) three separate glasshouse trials were undertaken. Each trial tested two different chemicals, both on their own and in combination with L. muscarium in sequential treatment. Designated quarantine glasshouse cubicles were used for experimental purposes.

For each trial thirty plants were infested with $B$. tabaci following the methods of Cuthbertson et al. (2003, 2005a). After egg laying had occurred and the adults had been removed, the infested plants were transferred in sealed boxes to the designated glasshouse cubicle. The plants (treatments) were arranged randomly throughout the cubicle and conditions maintained at $25^{\circ} \mathrm{C}$ for a further twelve days to allow the second instar to develop. After twelve days, the plants were divided into six groups, each containing five plants. Ten plants received a treatment of Savona, 10 plants a treatment of Certis Spraying oil and 10 a treatment of water as control. These were then left for $24 \mathrm{~h}$ after which: five of the Savona treated plants received an application of $L$. muscarium as did five of the Certis Spraying oil treated plants. Five of the water treated plants also received an application of L. muscarium. The remaining fifteen plants received an application of water. Both the pesticides and the fungus were applied using a hand held Hozelock ${ }^{\circledR}$ Polyspray hand held sprayer with cone nozzles. The procedure was repeated for each glasshouse trial to test the other chemical products. The data gained underwent analysis of variance.

\section{RESULTS AND DISCUSSION}

None of the treatments of chemical followed by fungus gave any significantly better control of whitefly compared to the chemical being used on its own (Fig. 1). Higher mortality was recorded following application of L. muscarium on foliage previously treated with Certis Spraying oil but it was not significantly better than the chemical control (d.f.= 1,19, $\mathrm{F}=3.13, \mathrm{P}=0.09$ ), the same phenomena was recorded for Oberon (d.f. $=1,19, \mathrm{~F}=2.14$, $\mathrm{P}=0.15$ ) and Agri-50E (d.f. $=1,19, \mathrm{~F}=1.46, \mathrm{P}=0.24$ ). However, on assessment of plants seven days post application of Agri-50E commercially unacceptable foliage damage was recorded (Fig. 2). Some Agri-50E treated leaves subsequently died and fell off the plants.

For the successful introduction of an IPM programme information is not only needed on the biology of the control agent in question (Cuthbertson and Murchie, 2004, 2007) but also on its' compatibility with other control agents, namely chemicals (Cuthbertson and Murchie, 2006). Clarification of the effects of chemical insecticides on the wide variety of biological control agents, including entomopathogenic fungi is necessary. However, to date there have been few in vitro tests. Different biopesticides based on $L$. muscarium are utilised on greenhouse crops to manage pests such as greenhouse whitefly, aphids and thrips in various European countries (Osborne and Landa, 1992). Also, timing of the control agent application for effective pest control has been shown to be critical, since the target instars as well as the ambient temperature/humidity can influence efficacy (Williams and Walters, 1994; Cuthbertson and Walters, 2005b; Cuthbertson et al., 2003, 2005a).

The implementation of an IPM scheme may require 


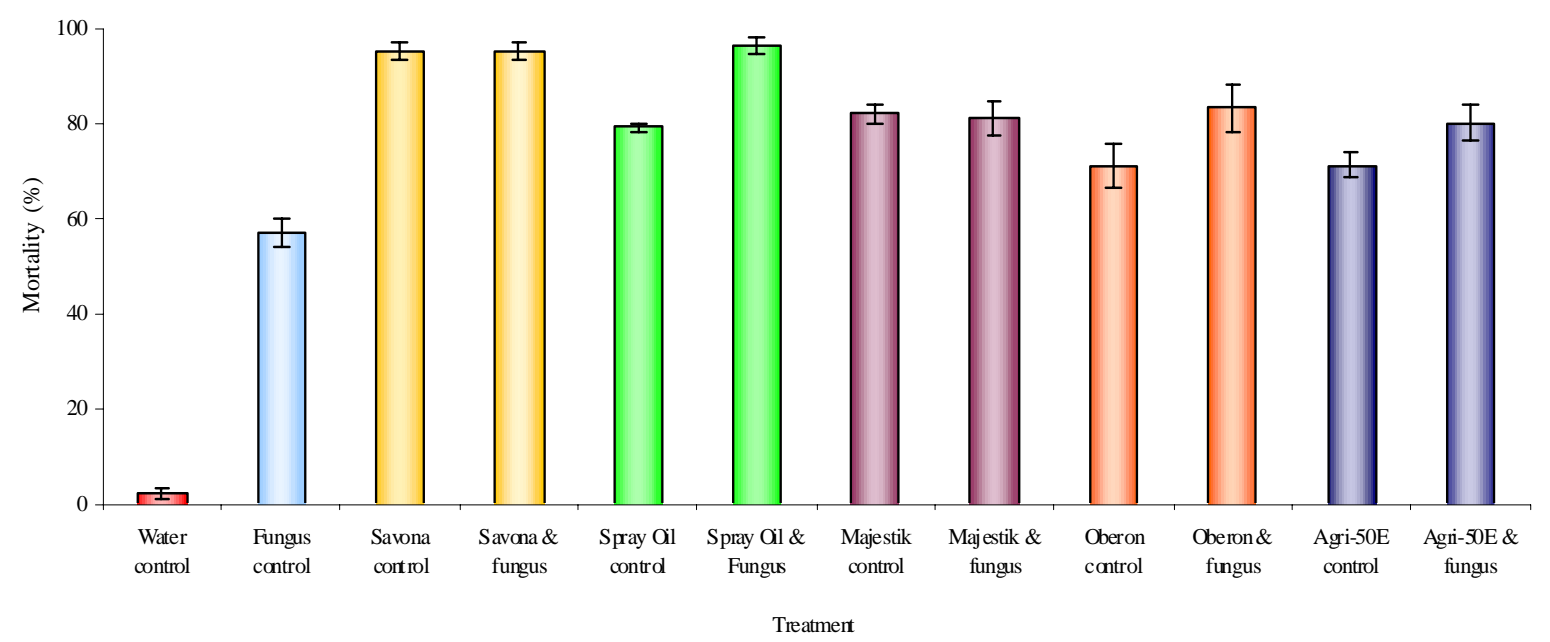

Fig. 1: Efficacy of Lecanicillium muscarium $\left(10^{7}\right.$ conidia/mL) against second instar Bemisia tabaci on tomato and verbena foliage under glasshouse conditions, $20{ }^{\circ} \mathrm{C}, 85 \%$ relative humidity. Mortality recorded after 7 days. Bars are standard errors of the means $( \pm$ SEM).

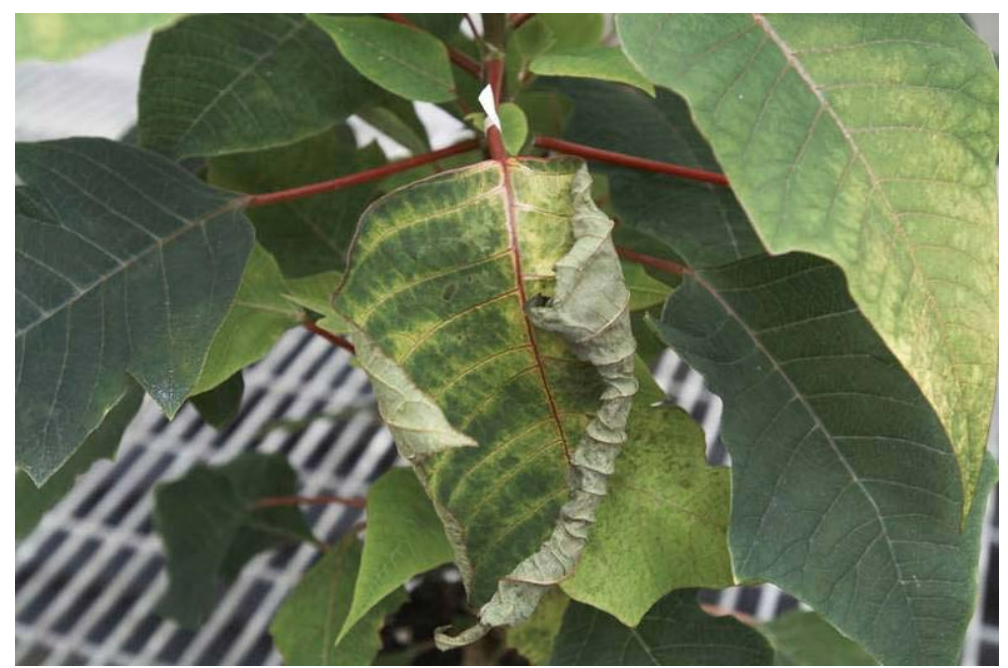

Fig. 2: Foliage damage recorded on poinsettia plants 7 days after spray application of Agri-50E (alginate/polysaccharide; $300 \mu \mathrm{L} / 100 \mathrm{~mL}$ water) within the glasshouse environment.

sequential rather than simultaneous applications of insecticides and entomopathogenic fungi. Apart from the study of Cuthbertson et al. (2005b) few previous studies have tested the effect of dry insecticide residue on fungal activity. In the current study, when L. muscarium was applied to plants sprayed $24 \mathrm{~h}$ earlier with a standard application of one of five contact insecticides, no significant reduction in infectivity (mycelial growth) was detected in any cases. Therefore, L. muscarium could be applied sequentially with Oberon, Savona, Certis spraying oil, Agri-50E and Majestik for the control of B. tabaci with second instars 
again proving highly susceptible to fungal attack, as found by Cuthbertson et al. (2005a, 2009b); Cuthbertson and Brown (2009). However, after application of Agri-50E commercially unacceptable foliage damage was recorded (Cuthbertson, A.G.S., personal observation). It is, therefore, unlikely that this product would be a candidate for further research on poinsettia plants. Other plant species may, however, prove to be more tolerant of this product. Further work could involve applying the fungus followed by insecticides at increasing time intervals to investigate potential protection of the fungus with increasing time before application of an insecticide. Testing for Agri-50E, which did produce a high level of B. tabaci mortality and which also has shown previously a high potential for direct mixing with $L$. muscarium (Cuthbertson et al., 2008a), phytotoxic effects on other plant species could prove useful in the development of IPM strategies.

\section{ACKNOWLEDGEMENTS}

The authors would thank Koppert Biological Systems Ltd, (UK) for supplying the formulation of Lecanicillium muscarium; Certis UK and Bayer CropScience for the supply of chemical products used in this study and Mr Richard Natt (Fera Horticultural Manager) and his team for the provision of plant material and maintenance of the quarantine glasshouse cubicle. The work was funded by Plant Health Division, Defra. Bemisia tabaci were held under quarantine license number: PHL 251B/5328(02/2006) Amended (04/2006).

\section{REFERENCES}

Ahmad, M.; Arif, M. I.; Ahmad, Z.; Denholm, I., (2002). Cotton whitefly (Bemisia tabaci) resistance to organophosphate and pyrethroid insecticides in Pakistan. Pest Manage. Sci., 58 (2), 203-208 (6 pages).

Alegbejo, M. D., (2000). Whitefly transmitted plant viruses in Nigeria. J. Sustain. Agri., 17 (2), 99-109 (11 pages).

Buxton, J.; Clarke, A., (1994). Evaluation of insecticide dips to control Bemisia tabaci on poinsettia cuttings. Pest. Sci., 42 (2), 141-142 (2 pages).

Cahill, M.; Byrne, F. J.; Denholm, I.; Devonshire, A. L.; Gorman, K. J., (1994). Insecticide resistance in Bemisia tabaci. Pest. Sci., 42 (2), 137-139 (3 pages).

Cahill, M.; Gorman, K.; Day, S.; Denholm, I.; Elbert, A.; Nauen, R., (1996). Baseline determination and detection of resistance to imidacloprid in Bemisia tabaci (Homoptera: Aleyrodidae). B. Entomol. Res., 86 (2), 343349 (7 pages).

Cannon, R. J. C.; Eyre, D.; MacLeod, A.; Matthews, L.; Malumphy, C.; Cheek, S.; Bartlett, P. W., (2005).
Interceptions and outbreaks of Bemisia tabaci in the UK. The BCPC International Congress - Crop Science and Technology 2005. Congress Proceedings Vol. 2, 10071012.

Cheek, S.; Macdonald, O., (1994). Management of Bemisia tabaci. Pest. Sci., 42 (2), 135-137 (3 pages).

Cuthbertson, A. G. S., (2005). Protecting the UK from alien pests. Bio. News, 32 (1), 9 (1 page).

Cuthbertson, A. G. S.; Brown, M. A., (2009). Issues affecting British honey bee biodiversity and the need for conservation of this important ecological component. Int. J. Environ. Sci. Tech., 6 (4), 695-699 (5 pages).

Cuthbertson, A. G. S.; Murchie, A. K., (2004). The phenology, oviposition and feeding rate of Anystis baccarum, a predatory mite in Bramley apple orchards in Northern Ireland. Exper. Appl. Acarol., 34 (2), 367-373 (7 pages).

Cuthbertson, A. G. S.; Murchie, A. K., (2006). The environmental impact of an orchard winter wash and early season pesticide applications on both a beneficial and a pest mite species in Bramley apple orchards. Int. J. Environ. Sci. Tech., 3 (3), 333-339 (7 pages).

Cuthbertson, A. G. S.; Murchie, A. K., (2007). A review of the predatory mite Anystis baccarum and its role in apple orchard pest management schemes in Northern Ireland. J. Entomol., 4 (2), 275-278 (4 pages).

Cuthbertson, A.G.S.; Walters, K.F.A., (2005a). Pathogenicity of the entomopathogenic fungus Lecanicillium muscarium against the sweetpotato whitefly Bemisia tabaci under laboratory and glasshouse conditions. Mycopathologia, 160 (2), 315-319 (5 pages).

Cuthbertson, A. G. S.; Walters, K. F. A., (2005b). Evaluation of exposure time of Steinernema feltiae against second instar Bemisia tabaci. Tests Agrochem. Cult., 26 (1), 3435 (2 pages).

Cuthbertson, A. G. S.; Head, J.; Walters, K. F. A.; Gregory, S. A., (2003). The efficacy of the entomopathogenic nematode Steinernema feltiae, against instars of Bemisia tabaci. J. Inverte. Pathol., 83 (2), 267-269 (3 pages).

Cuthbertson, A. G. S.; Walters, K. F. A.; Northing, P., (2005a). Susceptibility of Bemisia tabaci immature stages to the entomopathogenic fungus Lecanicillium muscarium on tomato and verbena foliage. Mycopathologia, 159 (1), 23-29 (7 pages).

Cuthbertson, A. G. S.; Walters, K. F. A.; Deppe, C., (2005b). Compatibility of the entomopathogenic fungus Lecanicillium muscarium and insecticides for eradication of sweetpotato whitefly, Bemisia tabaci. Mycopathologia, 160 (1), 35-41 (7 pages).

Cuthbertson, A. G. S.; Blackburn, L. F.; Northing, P.; Luo, W.; Cannon, R. J. C.; Walters, K. F. A., (2008a). Further compatibility tests of the entomopathogenic fungus Lecanicillium muscarium with conventional insecticide products for control of sweetpotato whitefly, Bemisia tabaci on poinsettia plants. Insect Sci., 15 (4), 355-360 (6 pages)

Cuthbertson, A. G. S.; Mathers, J. J.; Northing, P.; Prickett A. J.; Walters, K. F. A., (2008b). The integrated use of chemical insecticides and the entomopathogenic nematode, Steinernema carpocapsae (Nematoda: Steinernematidae), for the control of sweetpotato whitefly, 
Bemisia tabaci (Hemiptera: Aleyrodidae). Insect Sci., 15 (4), 447-453 (7 pages).

Cuthbertson, A. G. S.; Blackburn, L. F.; Northing, P.; Mathers, J. J.; Luo, L.; Walters, K. F. A. (2009a). Environmental evaluation of hot water treatments to control Liriomyza huidobrensis infesting plant material in transit. Int. J. Environ. Sci. Tech., 6 (2), 167-174 (8 pages).

Cuthbertson, A. G. S.; Blackburn, L. F.; Northing, P.; Luo, W.; Cannon, R. J. C.; Walters, K. F. A., (2009b). Leaf dipping as an environmental screening measure to test chemical efficacy against Bemisia tabaci on poinsettia plants. Int. J. Environ. Sci. Tech., 6 (3), 347-352 (6 pages).

Down, R. E.; Cuthbertson, A. G. S.; Mathers, J. J.; Walters, K. F. A., (2009). Dissemination of the entomopathogenic fungi, Lecanicillium longisporum and L. muscarium, by the predatory bug, Orius laevigatus, to provide concurrent control of Myzus persicae, Frankliniella occidentalis and Bemisia tabaci. Biol. Contr., 50 (2), 172-178 (7 pages).

Gerling, D.; Motro, U.; Horowitz, R., (1980). Dynamics of Bemisia tabaci (Gennadius) (Homoptera: Aleyrodidae) attacking cotton in the coastal plain of Israel. B. Entomol. Res., 70 (2), 213-219 (7 pages).

Hall, R. A., (1981). Laboratory studies on the effects of fungicides, acaricides and insecticides on the entomopathogenic fungus, Verticillium lecanii. Ent. Exper. Appl., 29 (1), 39-48 (10 pages).
Nomikou, M.; Janssen, A.; Schraag, R.; Sabelis, M. W., (2000). Phytoseiid predators as potential biological control agentV I RUBemisia tabaci. Exp. Appl. Acarol., 25 (2), 271-291 (20 pages).

Osborne, L. S.; Landa, Z., (1992) Biological control of whiteflies with entomopathogenic fungi. Fla. Entomol., 75 (4), 456-471 (16 pages).

Prabhaker, N.; Coudriet, D. L.; Meyerdirk, D. E., (1985). Insecticide resistance in the sweetpotato whitefly, Bemisia tabaci (Homoptera: Aleyrodidae). J. Econ. Entomol., 78 (4), 748-752 (5 pages).

Sharaf, N., (1986). Chemical control of Bemisia tabaci. Agri. Eco. Environ., 17 (2), 111-127 (16 pages).

Simón, B.; Cenis, J. L.; Demichelis, S.; Rapisarda, C.; Cacigli, P.; Bosco, D., (2003). Survey of Bemisa tabaci (Hemiptera: Aleyrodidae) biotypes in Italy with the description of a new biotype (T) from Euphorbia characias. B. Entomol. Res., 93 (2), 259-264 (6 pages)

Williams, E. C.; Walters, K. F. A., (1994). Nematode control of leafminers: Efficacy, temperature and timing. Brighton Crop Protection Conference: Pest Dis., 1 (3), 1079-1084 (5 pages).

Williams, E. C.; Walters, K. F. A., (2000). Foliar application of the entomopathogenic nematode, Steinernema feltiae against leafminers on vegetables. Biocontr. Sci. Tech., 10 (1), 61-70 (10 pages).

\section{AUTHOR (S) BIOSKETCHES}

Cuthbertson, A. G. S., Ph.D., Senior research entomologist, The Food and Environment Research Agency in York, England, UK. Email: andrew.cuthbertson@fera.gsi.gov.uk

Blackburn, L. F., B.Sc., Research entomologist, The Food and Environment Research Agency in York, England, UK. Email: lisa.blackburn@fera.gsi.gov.uk

Northing, P., M.Sc., Applied entomology team leader, The Food and Environment Research Agency in York, England, UK. Email: phil.northing@fera.gsi.gov.uk

Luo,W., Ph.D., Environmental statistician, The Food and Environment Research Agency in York, England, UK. Email: weiqi.luo@fera.gsi.gov.uk

Cannon, R. J. C., Ph.D., Senior plant health consultant, The Food and Environment Research Agency in York, England, UK. Email: ray.cannon@fera.gsi.gov.uk

Walters, K. F. A., Ph.D., Phytophthora research team leader, The Food and Environment Research Agency in York, England, UK. Email: keith.walters@fera.gsi.gov.uk

\section{How to cite this article: (Harvard style)}

Cuthbertson, A. G. S.; Blackburn, L. F.; Northing, P.; Luo,W.; Cannon, R. J. C.; Walters, K. F. A., (2010). Chemical compatibility testing of the entomopathogenic fungus Lecanicillium muscarium to control Bemisia tabaci in glasshouse environment. Int. J. Environ. Sci. Tech., 7 (2), 405-409. 